Japan and US both claim lead

Tokyo

NEC Corporation of Japan last week launched what it claimed to be the world's fastest supercomputer, raising fears in the United States that Japan has taken the lead in this key technology. But Cray Research Incorporated, the world's leading supercomputer manufacturer, is unperturbed. Officials of the US company's Japanese subsidiary say that Cray's fastest computer can already match the NEC supercomputer and that a new model will leave its Japanese competitor behind.

On the face of it, the top model in NEC's new SX-3 series of supercomputers is faster than anything Cray or anyone else has to offer. NEC's model SX-3/44, which has four central processing units, can, in theory, churn out 22,000 million floatingpoint operations per second (flops), a speed that is more than five times faster than Cray's fastest computer, the Y-MP 8/8 (see below). But in practical use, when computers operate far below peak speed, Cray may have the advantage.

Takehiko Kato, an engineer at Cray Research Japan Ltd, has simulated the performance of the two computers for a range of operating conditions. He claims that NEC's computer is comparatively slow at scalar processing (calculations on individual numbers) and can gain an advantage over Cray's computer only when performing calculations where vector processing (simultaneous calculations on lists of numbers) can be used more than 85 per cent of the time.

That means a Cray will be faster on almost all practical applications, including drug and chemical design, structural engineering and aerodynamics. Only in special fluid-dynamic calculations where vector processing exceeds 85 per cent will the high speed of NEC's computer be an advantage, Kato says. His simulation relies, however, on an estimate of $160 \mathrm{mil}$ lion flops for the NEC computer's scalar processing speed. NEC refuses to reveal a precise figure but claims Kato's estimate is "misleading".

Speed is only one of many factors considered by purchasers of supercomputers, according to Larry Smarr, director of the National Center for Supercomputing Applications in the University of Illinois at Urbana-Champaign. And speed comes comparatively low on the list of users' priorities if switching to a new system would require rewriting of software and computer codes (as a switch from Cray to NEC would require). A more important consideration, Smarr says, is the floating-point standard which the two competitors have adopted for their supercomputers.

Cray uses the IEEE standard that has been generally adopted by US scientists and engineers. But Japanese manufacturers, including NEC, are using the IBM standard for their supercomputers. Smarr says that as long as the Japanese keep to that standard, he would not buy one of their computers even if it were infinitely faster than a Cray because of software problems and incompatibility with computers already linked to his centre's supercomputer network.

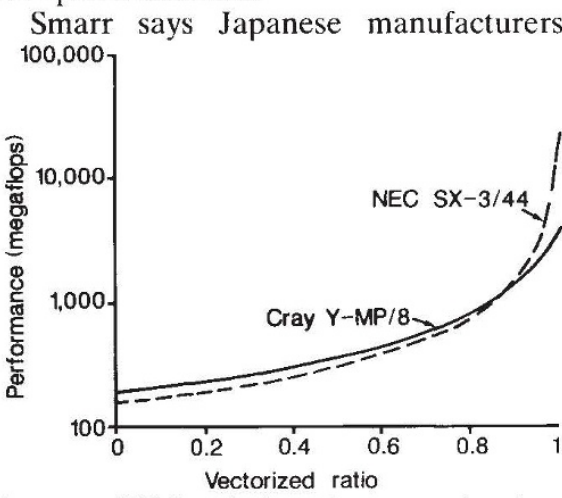

focus on IBM as their main competitor but this attitude is "schizophrenic" when at the same time they are trying to conquer the world of supercomputing, where IBM is a comparative outsider.

Nevertheless, Smarr says NEC's new computer has put Cray on a "tightrope" because the stockmarket may be "skittish" about any delay in the introduction of Cray's next model, the Cray-3. Cray officials, on the other hand, say the Cray-3 will give the company a decisive lead over NEC.

The Cray-3, which is expected to be on the market around the same time as NEC's new computer (shipments of which will begin in June next year), will be the first supercomputer to use logic chips made of the ultra-fast gallium arsenide, rather than silicon. It will be able to execute calculations much faster than NEC's new model because of its higher scalar processing speed (close to 1,000 million flops), Kato says, despite a lower top speed for vector processing $(16,000$ million flops).

But pricing strategies and technical back-up will be important in determining market share, particularly in Japan. Japan's huge electronics manufacturers have managed to seize the main share of the domestic market by aggressively slashing prices, something which a comparatively small company like Cray cannot afford to do. Nevertheless, despite a widely held perception that US supercomputers have fared badly in Japan, Cray has captured $40-50$ per cent of the market in the private sector, Kato says. And some Japanese car manufacturers have recently switched to Cray supercomputers for use in car design.

Cray has not done so well in the public sector, selling only two supercomputers to government research organizations since bidding was made more open to foreign companies in 1987. But most analysts expect the bulk of supercomputer sales in the future to be in the private sector, particularly in Japan and Europe where there are few large national research centres comparable to those of the United States. Smarr says that as supercomputers become cheaper they will begin to "percolate down into the Fortune 500 companies" from the giant corporations that use them now.

Cray and NEC agree with this assessment. NEC hopes to sell about 120 supercomputers in Japan and overseas over the next four years with 60 per cent going to the private sector. And Cray expects the Japanese market to more than double to 250 computers during the same period, again with the bulk of the sales in the private sector.

David Swinbanks

EUROPEAN SPACE PROGRAMME -

\section{Cornerstone laid in West Germany}

\section{Munich}

WEST Germany has begun the expansion of the ground control centre at Oberpfaffenhofen, near Munich, for future space station and spacelab missions. The foundation stone for the new centre was laid on 4 April. Construction will proceed in two phases.

The West German Research Ministry will invest DM85 million by 1991 to prepare for the next West German spacelab mission. A new computer centre and robotics centre will also be created. The European Space Agency will then invest an estimated DM100 million to build a control centre for the European space station Columbus.

Steven Dickman

\section{AUSTRALIA}

\section{Science fiction for science students}

\section{Sydney}

SCIENCE students at Murdoch University in Western Australia are to be given a foundation course in science fiction in an attempt to wean them from television and videos. The only books they ever read are textbooks, according to their course coordinators, creating a "literacy problem".

The course on 'Life and the Universe' will include Dune by Frank Herbert and Ringworld Engineers by Larry Niven in its reading material. One of the course organizers, David Macey, says that students are "reluctant to acknowledge they have a problem with literacy. A short science fiction novel can move them sideways into general reading and general biological concepts."

Tania Ewing 